\title{
Enhancement of the CXCL12/CXCR4 axis due to acquisition of gemcitabine resistance in pancreatic cancer: effect of CXCR4 antagonists
}

Mamoru Morimoto, Yoichi Matsuo*, Shuji Koide, Ken Tsuboi, Tomoya Shamoto, Takafumi Sato, Kenta Saito, Hiroki Takahashi and Hiromitsu Takeyama

\begin{abstract}
Background: The CXCL12-CXCR4 signaling axis in malignant tumor biology has increased in importance, and these peptides are implicated in tumor growth, invasion and metastasis. The aim of our study was to examine the important role of the axis in pancreatic cancer ( $\mathrm{PaCa}$ ) cells' relationship with stromal cells in gemcitabine-resistant (GEM-R) tumors and to confirm the effectiveness of CXCR4 antagonists for the treatment of GEM-R PaCa cells.

Methods: We established two GEM-R PaCa cell lines using MIA PaCa-2 and AsPC-1 cells. The expression of CXCR4 mRNA in PaCa cells and the expression of CXCL12 mRNA in fibroblasts were examined by reverse transcription polymerase chain reaction (RT-PCR). The expression of CXCR4 protein in PaCa cells was examined by immunosorbent assay (ELISA) and immunocytochemistry. Using Matrigel invasion assays and animal studies, we then examined the effects of two CXCR4 antagonists, AMD1 1070 and KRH3955, on the invasiveness and tumorigenicity of GEM-R PaCa cells stimulated by CXCL12.

Results: We found that the expression of CXCR4 in GEM-R PaCa cells was significantly enhanced by GEM but not in normal GEM-sensitive (GEM-S) PaCa cells. In RT-PCR and ELISA assays, the production and secretion of CXCL12 from fibroblasts was significantly enhanced by co-culturing with GEM-R PaCa cells treated with GEM. In Matrigel invasion assays, the invasiveness of GEM-R PaCa cells treated with GEM was significantly activated by fibroblast-derived CXCL12 and was significantly inhibited by CXCR4 antagonists, AMD11070 and KRH3955. In vivo, the tumorigenicity of GEM-R PaCa cells was activated by GEM, and it was significantly inhibited by the addition with CXCR4 antagonists.

Conclusions: Our findings demonstrate that the CXCL12-CXCR4 signaling axis plays an important role in PaCa cells' resistance to GEM. CXCR4 expression was significantly enhanced by the exposure to GEM in GEM-R PaCa cells but not in GEM-S PaCa cells. Furthermore, CXCR4 antagonists can inhibit the growth and invasion of GEM-R PaCa cells. These agents may be useful as second-line chemotherapy for GEM-R PaCa in the future.
\end{abstract}

Keywords: Pancreatic cancer, Gemcitabine resistant, CXCR4, CXCL12, CXCR4 antagonist

\footnotetext{
* Correspondence: matsuo@med.nagoya-cu.ac.jp

Department of Gastroenterological Surgery, Nagoya City University Graduate

School of Medical Science, Kawasumi 1, Mizuho-cho, Mizuhoku, Nagoya

467-8601, Japan
} 


\section{Background}

Pancreatic cancer $(\mathrm{PaCa})$ has the worst survival rate of all cancers. PaCa remains the fourth leading cause of cancer death in the United States [1]. With surgery, radiotherapy and chemotherapy, the 5-year survival rate of patients with $\mathrm{PaCa}$ remains less than $5 \%$ [2]. There has been some progress in the use of improved diagnostic methods and development of novel targeted therapies. Gemcitabine (GEM) was approved in 1997 as a first-line chemotherapeutic drug for patients with locally advanced or metastatic PaCa [3]. GEM remains the standard treatment for pancreatic cancer patients. However, it has not proven very effective clinically, and improvement in a patient's survival undergoing GEM therapy is minimal [4]. Clinical experience has shown that there is a transient effect of GEM therapy on $\mathrm{PaCa}$ after beginning chemotherapy; however, resistance to GEM readily appears.

Recently, the role of chemokines in malignant tumor biology has increased in importance because studies have shown that these peptides may influence tumor growth, invasion, and metastasis [5-14]. We have reported that two chemokines, CXCL8 and CXCL12, play important roles in the angiogenesis of $\mathrm{PaCa}$ [5]. The functional roles of CXCR4 in cell migration $[14,15]$ and cell proliferation [16] in response to CXCL12 have been suggested in malignant diseases. Furthermore, activation of the CXCL12-CXCR4 signaling axis is involved in conferring chemoresistance to $\mathrm{PaCa}$ cells through potentiation of intrinsic survival mechanisms [17].

CXCR4 antagonists were initially developed as new drugs for the treatment of HIV-1 infection [18-20]. With the rapid increase in our knowledge of non-HIVrelated functions of CXCR4, other potential applications for treatment of cancer have emerged and have gradually replaced the original intent to use CXCR4 antagonists as anti-HIV drugs. There have been several reports describing the effects of CXCR4 antagonists (AMD3100, AMD11070 and KRH3955) in the treatment of malignant tumors, including breast cancer [21], small cell lung cancer [22], cholangiocarcinoma [23], gastric cancer [24] and pancreatic cancer [17, 25, 26]. However, it has not been reported whether the activated CXCL12CXCR4 signaling axis plays an important role in $\mathrm{PaCa}$ cells' resistance to GEM and whether CXCR4 antagonists can inhibit the activated signaling axis in GEMresistant (GEM-R) PaCa in vitro and in vivo.

The purpose of this study was to determine the roles of the CXCL12-CXCR4 signaling axis in the relationship between tumor and stromal cells in GEM-R PaCa. Furthermore, we examined the therapeutic significance of CXCR4 antagonists, AMD11070 and KRH3955, in preventing the rescue effect of activated CXCL12-CXCR4 signaling. This is the first report that reveals the important role of the CXCL12-CXCR4 signaling axis in enhancing resistance to GEM and the effect of CXCR4 antagonists on GEM-resistant PaCa cells.

\section{Methods \\ Cell lines and culture conditions}

Human pancreatic cancer $(\mathrm{PaCa})$ cell lines MIA $\mathrm{PaCa}-2$ and AsPC-1 and human dermal fibroblast were obtained from the American Type Culture Collection (Rockville, $\mathrm{MD})$ and Kurabo Industries (Osaka, Japan), respectively. The cell lines were maintained at $37{ }^{\circ} \mathrm{C}$ with $5 \% \mathrm{CO}_{2}$ in a humidified atmosphere. The following media were used: (1) MIA PaCa-2 cells were cultured in Dulbecco's Modified Eagle's Medium (DMEM), (2) AsPC-1 cells were incubated in Roswell Park Memorial Institute (RPMI-1640) medium (Sigma Aldrich, St Louis, MO, USA) supplemented with $10 \%$ fetal bovine serum (FBS) and antibiotics and (3) fibroblasts (FB) were maintained in fibroLife S2 Comp kit (Kurabo Industries Ltd., Osaka, Japan) supplemented with $2 \%$ FBS.

\section{Establishment of PaCa cell lines resistant to gemcitabine} Gemcitabine (GEM) was purchased from Toronto Research Chemicals, Inc. (Toronto, Ontario, Canada). First, we determined the half maximal inhibitory concentration (IC50) of GEM for MIA PaCa-2 or AsPC-1 cells using the Premix WST-1 Cell Proliferation Assay System (Takara Bio, Japan) according to the manufacturer's instruction. Briefly, MIA PaCa-2 or AsPC-1 cells were seeded at a density of $2 \times 10^{3}$ cells per $100 \mu \mathrm{L}$ in 96-well plates and allowed to adhere overnight. Then, cultures were re-fed with fresh media containing various concentrations of GEM. After $72 \mathrm{~h}$ of incubation, absorbance was measured at $450 \mathrm{~nm}$ in each well using a SpectraMax 340 spectrophotometer (Molecular Devices, CA, USA). The IC50 of GEM for each pancreatic cancer line was determined by constructing a dose-response curve. Each pancreatic cancer cell line was passaged in the cell lines' IC50 concentration of GEM for 2 to 3 weeks. After passage, we again determined the cell lines' IC50 value for GEM. Then, each pancreatic cancer cell line was passaged in the cell lines' re-determined IC50 concentration of GEM for 2 to 3 weeks. The process was repeated at increasing doses of GEM until the cell lines demonstrated at least a 50 -fold greater IC50 value for GEM than the parental cell lines. The resultant cell lines were resistant to GEM at a concentration of $20 \mu \mathrm{M}$.

\section{Proliferation assay}

The proliferation assay was conducted using the Premix WST-1 Cell Proliferation Assay System (Takara Bio, Japan) according to the manufacturer's instruction. Briefly, GEM-resistant (GEM-R) and GEM-sensitive (GEM-S) MIA PaCa-2 or AsPC-1 cells were seeded at a density of $2 \times 10^{3}$ cells per $100 \mu \mathrm{L}$ in 96-well plates and 
allowed to adhere overnight. Then, cultures were refed with fresh media containing various concentrations $(0-100 \mu \mathrm{M})$ of GEM. After $72 \mathrm{~h}$ of incubation, absorbance was measured at $450 \mathrm{~nm}$ in each well using a SpectraMax 340 spectrophotometer.

\section{Enzyme-linked immunosorbent assays (ELISAs)}

The expression of CXCR4 protein by GEM-R/S MIA PaCa-2 and AsPC-1 cells was examined using the CXCR4 ELISA kit (USCN Life Science Inc., Wuhan, China) according to the manufacturer's instructions. A total of $1 \times 10^{5}$ GEM-R/S cells were seeded in each $100 \mathrm{~mm}$ dish. Then, we added different concentrations of GEM $(0-20 \mu \mathrm{M})$, and the cells were incubated for $72 \mathrm{~h}$. After indicated treatments, cell lysates were prepared. A total of $150 \mu \mathrm{g}$ of protein was taken for ELISA assay. Similarly, CXCL12 levels in the supernatant from FB co-cultured with GEM-R/S MIA $\mathrm{PaCa}-2$ cells were determined using the CXCL12 ELISA kit (R\&D, Minneapolis, MN, USA) according to the manufacturer's instruction. To determine the synergistic effect of the tumor-stromal interaction, we cultured FB $\left(1.0 \times 10^{6}\right.$ cells in 6 -well plates $)$ with or without GEM-R/S $\left[1.0 \times 10^{6}\right.$ cells on inserts with 0.4 $\mu \mathrm{m}$ pores (Thermo Scientific, Rockford, IL, USA)] for $72 \mathrm{~h}$ using a double chamber method. After the incubation, the media were collected and microfuged at $1500 \mathrm{rpm}$ for $5 \mathrm{~min}$ to remove particles. The supernatants were frozen at $-80{ }^{\circ} \mathrm{C}$ until use. A total of $150 \mu \mathrm{g}$ of the protein was taken for ELISA assay.

\section{RNA isolation and reverse transcription polymerase chain reaction (RT-PCR)}

Total RNA was extracted from cell pellets using an RNeasy Plus Mini Kit (Qiagen, TX, USA), and RT-PCR was performed using Superscript III First-strand Synthesis SuperMix for qRT-PCR (Invitrogen, Carlsbad, CA, USA). The concentration of each cDNA was measured with a NanoDrop1000 (Thermo Fisher Scientific, DE, USA) and adjusted to $40 \mathrm{ng} / \mathrm{mL}$ with diethylpyrocarbonate (DPEC)- treated water. We performed real-time PCR with FAM-labeled TaqMan probes (CXCR4: Hs00607978_s1; CXCL12: Hs03676656_mH; GAPDH: Hs99999905_m1; CXCR7: Hs00664172_s1 (Applied Biosystems, Foster City, CA, USA)) and TaqMan Universal Master Mix (Applied Biosystems) using Chromo4 (BioRad, MA, USA). PCR was carried out by an initial incubation at $50{ }^{\circ} \mathrm{C}$ for $2 \mathrm{~min}$, followed by denaturation at $95{ }^{\circ} \mathrm{C}$ for $10 \mathrm{~min}$ and 50 cycles of $95{ }^{\circ} \mathrm{C}$ for $15 \mathrm{~s}$ and $60{ }^{\circ} \mathrm{C}$ for $1 \mathrm{~min}$.

\section{Immunocytochemical staining}

The expression of CXCR4 protein in GEM-R/S MIA $\mathrm{PaCa}-2$ cells was detected by immunostaining. Three days after treating with GEM, GEM-R/S PaCa cells were washed twice with ice-cold PBS, fixed in $4 \%$ paraformaldehyde for $20 \mathrm{~min}$ at room temperature and washed twice with ice-cold PBS. The cells were then incubated for $15 \mathrm{~min}$ in PBS containing $0.5 \%$ Triton X-100, washed with PBS, blocked in $1 \%$ BSA in PBS for $30 \mathrm{~min}$ and incubated with rabbit anti-CXCR4 polyclonal antibody (1:100, Abcam, Cambridge, UK) at $4{ }^{\circ} \mathrm{C}$ overnight. Subsequently, the cells were washed with PBS, incubated with Alexa Fluor 488 goat anti-rabbit IgG $(\mathrm{H}+\mathrm{L})$ (1:100, Life Technologies, Carlsbad, CA) and mounted with Prolong ${ }^{\odot}$ Gold Antifade Reagent with DAPI (Life Technologies, Carlsbad, CA).

\section{Invasion assay}

In vitro invasion assays were performed using the BD Bio-Coat Matrigel invasion assay system (BD Biosciences, Franklin Lakes, NJ) according to the manufacturer's instructions. Briefly, GEM-R/S cells $\left(2.5 \times 10^{4}\right.$ cells) were seeded into the Matrigel precoated Transwell chambers consisting of polycarbonate membranes with $8.0 \mu \mathrm{m}$ pores. The Transwell chambers were then placed into 6-well plates, into which we added basal medium only or basal medium containing various concentrations of recombinant CXCL12. After incubating GEM-R/S cells for $22 \mathrm{~h}$, the upper surface of the Transwell chambers was wiped with a cotton swab and the invading cells were fixed and stained using Diff-Quick cell staining kit (Dade Behring, Inc., Newark, DE). The number of invading cells was counted in 5 random microscopic fields $(200 \times)$. To confirm whether the invasive potency of $\mathrm{PaCa}$ cells was increased by FB-derived CXCL12 and inhibited by the CXCR4 antagonists, AMD11070 (AdooQ BioScience, Irvine, CA) and KRH3955 (Kureha Chemical Industry, Tokyo, Japan), we performed an invasion assay for GEM-R/S cells using a double-chamber method. Briefly, we co-cultured GEM-R/S cells $\left(2.5 \times 10^{4}\right.$ cells in Transwell chambers) with FB $\left(1 \times 10^{4}\right.$ cells in 6well plates) blocking with or without CXCR4 antagonists, AMD11070 and KRH3955, at a concentration of $1 \mu \mathrm{M}$. After incubation for $22 \mathrm{~h}$, invading cells were counted in the same manner.

\section{Animals}

All animal studies were conducted in accordance with the guidelines established by the internal Institutional Animal Care and Use Committee and Ethics Committee guidelines of Nagoya City University.

Female BALB/c nu-nu mice (5 to 6 weeks old) were obtained from Charles River (Sulzbach, Germany). The animals were housed in standard Plexiglas cages (8 per cage) in a room maintained at constant temperature and humidity and in a $12 \mathrm{~h} / 12 \mathrm{~h}$ lightdark cycle. Their diet consisted of regular autoclaved chow and water ad libitum. All animal experiments 
were approved by the authorities in our institute and were in compliance with the institution's guidelines.

\section{Subcutaneous transplant animal model}

A total of $2 \times 10^{7}$ MIA PaCa-2 cells were injected subcutaneously into mice. Tumors were measured weekly and tumor volume was documented. Tumors were allowed to grow until they reached a volume of $1 \mathrm{~cm}^{3}$, at which time the mice were sacrificed and the tumor tissue was harvested. For serial transplantation, the harvested tumor tissues were chopped into pieces approximately 1 to $2 \mathrm{~mm}^{3}$ in dimension. Tumor pieces were implanted subcutaneously into the mice. GEM and CXCR4 antagonists were administered 3 weeks after tumor implantation as follows: $25 \mathrm{mg}$ GEM/kg body weight, $1 \mathrm{mg}$ AMD11070, and $1 \mathrm{mg}$ KRH3955/kg body weight were given intraperitoneally every week.

\section{Experimental protocol}

Mice were randomly assigned to 1 of the following 6 treatment groups (4 mice per group): group I was not given any drugs; group II was given GEM alone; group III was given AMD11070 alone; group IV was given KRH3955 alone; group V was given GEM plus AMD11070; group VI was given GEM plus KRH3955. Therapy was continued for 4 weeks, and the mice were sacrificed 2 weeks later. We calculated the tumor volume according to the following formula: tumor volume $\left(\mathrm{mm}^{3}\right)=\mathrm{d}^{2} \mathrm{x} \mathrm{D} / 2$, where $\mathrm{d}$ and $\mathrm{D}$ were the shortest and longest diameter, respectively. Finally, the tumors were harvested from mice after the treatment and fixed in formaldehyde for further analysis.

\section{Immunohistochemical analysis}

Formalin-fixed, paraffin-embedded mouse tumor tissue sections were mounted on 3-amino-propyltriethoxylsilanecoated slides. Dewaxed paraffin sections were placed in a microwave (10 min, 600 watts) to recover antigens before staining. Antibodies used were as follows: rabbit antiCXCR4 polyclonal antibody, rabbit anti-SDF- $1 \alpha$ polyclonal antibody (1:50) and, rabbit anti-Hypoxia-Inducible Factor (HIF)-1 $\alpha$ monoclonal antibody (1:100) (Abcam, Cambridge, UK), followed by secondary antibodies conjugated to biotin. Peroxidase-conjugated streptavidin was used with 3,3-diaminobenzidine tetrahydrochloride (DAB) (Biocare Medical, Concord, CA, USA) as the chromogen for detection. Hematoxylin was used for nuclear counterstaining. CXCR4-positive $\mathrm{PaCa}$ cells, CXCL12-positive stromal cells and HIF$1 \alpha$-positive PaCa cells exhibited DAB-positive (brown) staining; negative cells were stained with the hematoxylin counterstain only. The number of CXCR4-immunoreactive cells in mouse specimens was expressed as a percentage of the total number of cells that were randomly counted in 10 fields at $\times 400$ magnification. For each image, a color deconvolution method was used to isolate CXCL12positive and HIF-1 $\alpha$-positive DAB-stained cells from CXCL12-negative and HIF-1 $\alpha$-negative hematoxylinstained cells. DAB and hematoxylin were digitally separated using ImageJ software (version 1.46c; WS Rasband, National Institutes of Health, Bethesda, MD, USA, http://rsb.info.nih.gov/ij/) and an ImageJ plugin for color deconvolution that calculated the contribution of DAB and hematoxylin, based on stain-specific red-green-blue (RGB) absorption. Following deconvolution, the scale was set to the $200 \mu \mathrm{m}$ scale bar on each image. The measurement parameter was integrated optical density (IOD). Optical density was calibrated and the area of interest was set as follows: hue, 0-30; saturation, 0-255; intensity, $0-255$. Then, the values were counted. The IOD was $\log _{10}$ transformed [27].

\section{Nuclear factor-kappa B (NF-KB) activity}

The activity of NF- $\mathrm{kB}$ was measured using NF- $\mathrm{kB}$ (p65) transcription factor assays. A total of $1 \times 10^{5}$ GEM-R/S cells of MIA PaCa-2 cells were seeded in 100-mm dishes and incubated with different concentrations of GEM for $72 \mathrm{~h}$. After indicated treatments, nuclear proteins were extracted using NE-PER Nuclear and Cytoplasmic Extraction Reagents (Thermo Scientific, IL, USA). The concentrations of nuclear proteins were measured using a Pierce BCA Protein Assay Kit (Thermo Scientific), and protein concentrations were adjusted for equal loading $(200 \mu \mathrm{g} / \mathrm{mL})$. The levels of NF- $\mathrm{kB}$ p65 protein detected with the NF- $\mathrm{BB}$ p65 ELISA kit (Invitrogen, USA) according to the manufacturer's instructions.

\section{Statistical analysis}

All measurement data were expressed as means \pm standard deviation (SD). They were calculated for experiments performed in triplicate (or more). Multiple group comparisons were performed by using one-way analysis of variance (ANOVA) followed by the Dunnett test, and Bonferroni tests were used for post hoc 2-sample comparisons. A two-sided $p$-value of less than 0.05 was considered statistically significant. All statistical analyses were performed using EZR (Saitama Medical Center, Jichi Medical University, http://www.jichi.ac.jp/saitama-sct/SaitamaHP.files/statmedEN.html; Kanda, 2012), a graphical user interface for $\mathrm{R}$ (The $\mathrm{R}$ Foundation for Statistical Computing, Vienna, Austria, version 2.13.0). More precisely, EZR is a modified version of R Commander (version 1.6-3) that was designed to add statistical functions frequently used in biostatistics. 


\section{Results}

The effect of GEM on the proliferation of GEM-R PaCa cells in vitro

We first determined how GEM affected the proliferation of $\mathrm{PaCa}$ cells that were sensitive or resistant to the drug. We used 2 GEM-R PaCa cell lines, MIA $\mathrm{PaCa}-2$ and AsPC-1. With these 2 cell lines, we found that GEM significantly inhibited GEM-S cell proliferation in a dose-dependent manner $(P<0.01)$; however, it could not inhibit GEM-R cell proliferation at the doses used (Fig. 1a, MIA PaCa-2; Fig. 1b, AsPC-1).

The expression of CXCR4 in GEM-R PaCa cells was enhanced by GEM

The expression of CXCR4 protein by PaCa cells was examined by means of ELISA assays. In MIA PaCa-2, the expression of CXCR4 protein by GEM-S cells was significantly inhibited by GEM in a dose-dependent manner $(P<0.01)$ (Fig. 2a). In contrast, the expression of CXCR4 protein by GEM-R cells showed a significant dose-dependent enhancement by GEM $(P<0.01)$ (Fig. 2b). In AsPC-1, there was no change of expression of CXCR4 protein during GEM treatment of sensitive cells (Fig. 2c). However, the expression of CXCR4 protein by resistant cells significantly increased in the presence of GEM in a fashion that varied with the dose $(P<0.01)$ (Fig. 2d). Furthermore, in RT-PCR, there was no change of CXCR4 mRNA levels by GEM treatment of sensitive MIA PaCa-2 cells (Fig. 3a). However, the level of CXCR4 mRNA in GEM-R cells was significantly elevated by treatment with GEM in a dosedependent manner $(P<0.01)$ (Fig. 3b).

In immunocytochemical assays, staining of CXCR4 protein was primarily found in the cell membrane of GEM-S and GEM-R cells. These cells were treated with GEM at concentrations of $0 \mu \mathrm{M}, 1 \mu \mathrm{M}, 10 \mu \mathrm{M}$ and $20 \mu \mathrm{M}$. The staining of CXCR4 in GEM-R cells was enhanced by GEM as the dose was increased [CXCR4 (green) and DAPI (blue)] (Fig. 3c-j).

\section{The secretion of CXCL12 from FB was enhanced by} co-culturing with GEM-R PaCa cells treated with GEM To investigate the function of the CXCL12-CXCR4 signaling axis, we determined whether the secretion of CXCL12 from FB was enhanced when FB were cocultured with $\mathrm{PaCa}$ cells. The expression of CXCL12 mRNA in FB was significantly enhanced by coculturing with GEM-R PaCa cells treated with GEM $(P<0.01)$ (Fig.4a). Furthermore, the secretion levels of CXCL12 protein from FB were significantly enhanced by co-culturing with GEM-R PaCa cells treated with GEM $(P<0.01)$ (Fig. 4b).

The role of CXCR4 in CXCL12-mediated invasiveness of GEM-R PaCa cells: inhibition by CXCR4 antagonists When GEM-R PaCa cells were exposed to GEM, the invasive behavior of these cells was significantly enhanced by stimulation with recombinant CXCL12 $(P<0.01)$ (Fig. 5a). Moreover, the enhanced invasive behavior of GEM-R PaCa cells was significantly inhibited by exposure to CXCR4 antagonists $(P<0.01)$ (Fig. 5b). Furthermore, when GEM-R PaCa cells were exposed to GEM, the invasive behavior of these cells was significantly elevated by co-culturing with $\mathrm{FB}(P<0.01)$ (Fig. 5c). The activated invasive behavior of GEM-R PaCa cells was significantly inhibited by treatment with neutralizing CXCR4 antagonists $(P<0.01)$ (Fig. 5d). Photographs show alterations of invasive behavior of the $\mathrm{PaCa}$ cells in each treatment group (Additional file 1: Figure S1).

GEM enhanced the growth of GEM-R PaCa cells in a nude mouse model: inhibition by CXCR4 antagonists

On the basis of these results, we asked whether CXCR4 antagonists affected the growth of GEM-R PaCa cells in
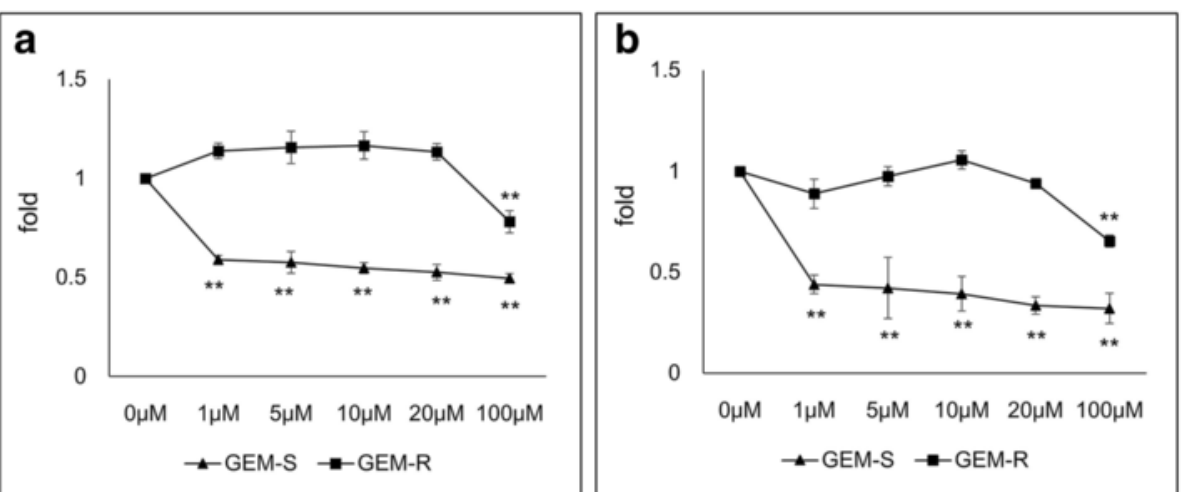

Fig. 1 Effect of GEM on the proliferation of GEM-R and GEM-S PaCa cell lines. a The proliferation of GEM-R and GEM-S MIA PaCa-2 cells (b) and AsPC-1 cells was determined using WST-1 assays. Values are expressed as means \pm SD. Statistical significance was analyzed by using one-way ANOVA followed by Dunnett's test. ${ }^{* *}, P<0.01 ;{ }^{*}, P<0.05$ versus the control $(0 \mu \mathrm{M})$ 


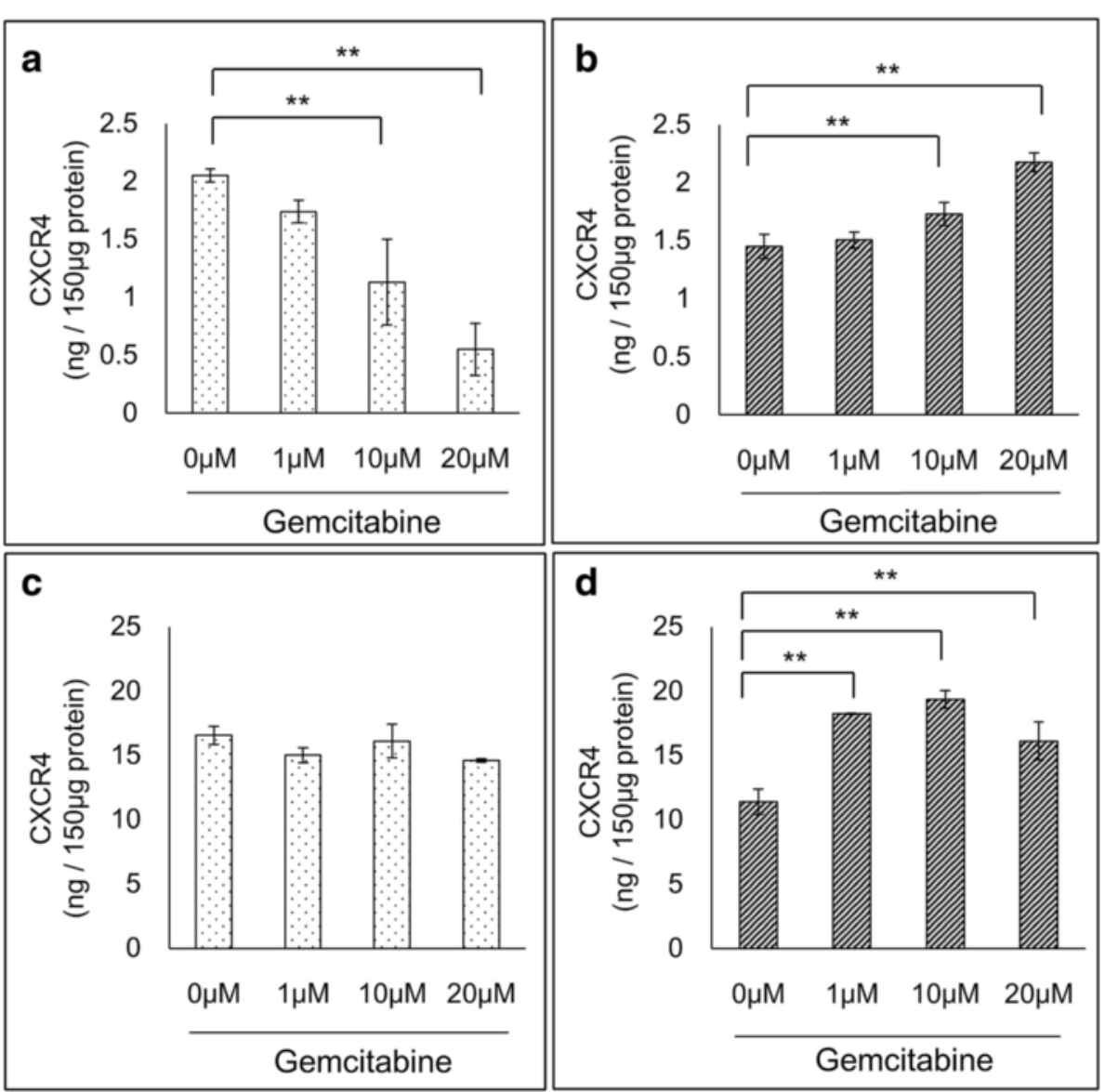

Fig. 2 Alteration of CXCR4 protein expression in PaCa cells by GEM. PaCa cells were treated with different concentrations of GEM (0-20 $\mu M)$ for $72 \mathrm{~h}$. The concentrations of CXCR4 protein in a MIA PaCa-2 GEM-S, b MIA PaCa-2 GEM-R, c AsPC-1 GEM-S d and AsPC-1 GEM-R were measured by ELISA. Values are expressed as means \pm SDs. Multiple comparisons were performed by using one-way ANOVA followed by Dunnett's test. ${ }^{*}, P<0.01 ;{ }^{*}, P<0.05$ versus control $(0 \mu \mathrm{M})$

vivo, either alone or in combination with GEM. Six experimental conditions were tested (see Methods, Experimental Protocol). Using mice implanted with GEM-R 4 weeks earlier, the final tumor volume of group II (GEM+) was significantly greater than that found in any of the other groups $(P<0.01)$ (Fig. 6a). With GEM-S PaCa cells, the tumor volume of group I (no treatment) was significantly greater than groups II $(\mathrm{GEM}+), \mathrm{V}$ $(\mathrm{GEM}+\mathrm{AMD}+)$ and VI $(\mathrm{GEM}+\mathrm{KRH}+) \quad(P<0.01)$ (Fig. 6b).

In GEM-R PaCa cells, tumor volumes in group $\mathrm{V}$ $(\mathrm{GEM}+\mathrm{AMD}+)$ and groupVI $(\mathrm{GEM}+\mathrm{KRH}+)$ were significantly less than groups III (AMD+) and IV (KRH+) $(P<0.05)$ and group I (no treatment) $(P<0.01)$ (Fig. 6c). There was no significant difference among groups I (no treatment), III (AMD+) and IV (KRH+). However, tumor volume in group II (GEM+) was significantly smaller than groups III (AMD+) and IV $(\mathrm{KRH}+)(P<$ 0.05) (Fig. 6d).
The photographs show the differences of the final tumor volume of all groups in GEM-R PaCa cells (Fig. 6e) and in GEM-S PaCa cells (Fig. 6f).

\section{Immunohistochemical analysis of CXCR4 and CXCL12 in implanted tumor tissue}

CXCR4 protein was primarily identified in the cell membrane of $\mathrm{PaCa}$ cells. In contrast, it was not detected in normal stromal cells of noncancerous regions in $\mathrm{PaCa}$ tissue. Staining of CXCR4 protein in GEM-R cells treated with GEM was greatly enhanced (Fig. $6 g-j)$. Significantly more CXCR4-positive cells were observed in GEM-R cells treated with GEM than GEM-R cells lacking such treatment $(P<0.05)$, GEM-S treated with GEM $(P<0.01)$ and GEM-S without GEM treatment $(P<0.01)$ (Additional file 2: Figure S2A). Staining of CXCL12 protein primarily occurred in the cytoplasm of stromal cells around $\mathrm{PaCa}$ cells, but it was not detected in $\mathrm{PaCa}$ tissues. Staining of CXCL12 protein was greatly enhanced 

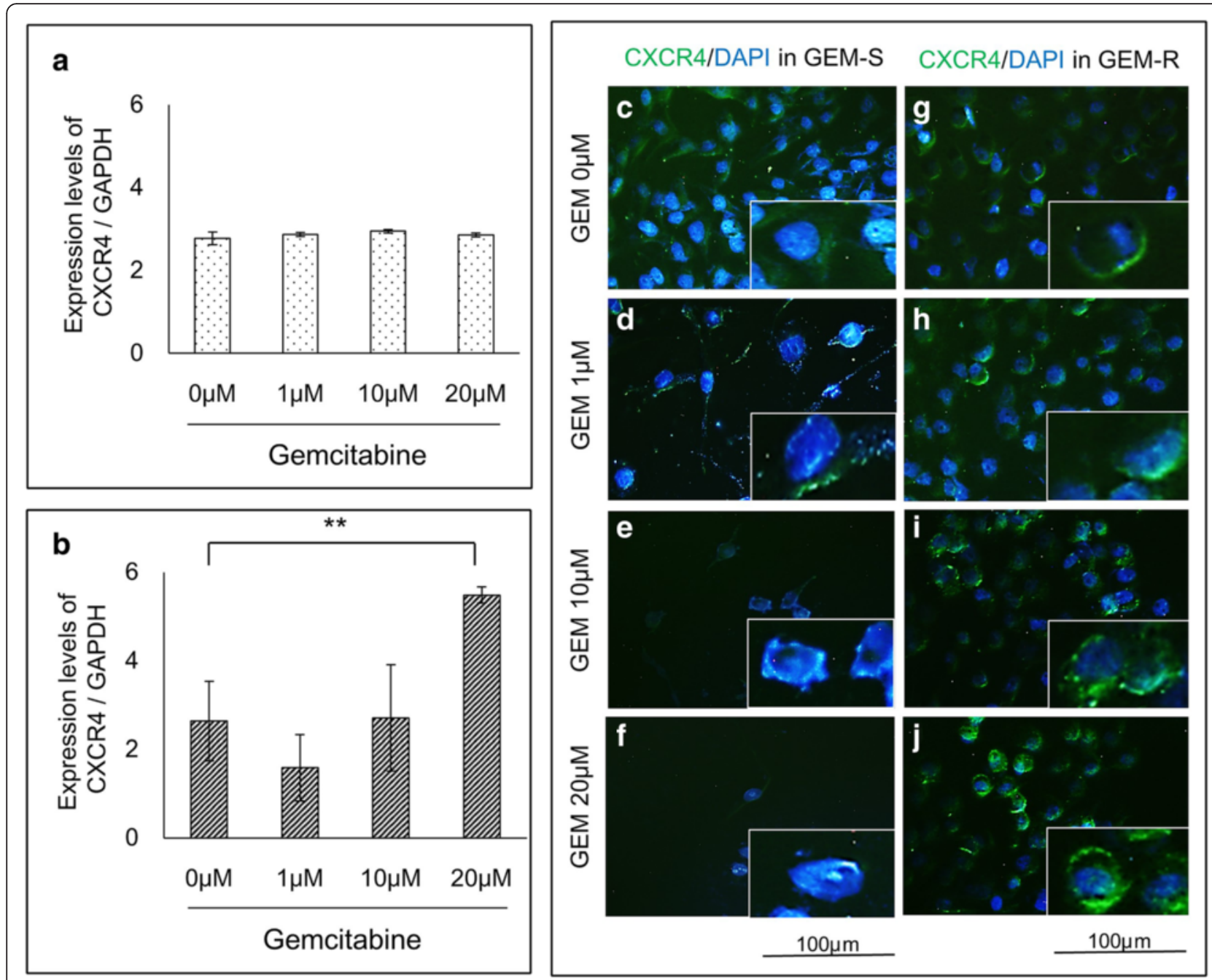

Fig. 3 Alteration of CXCR4 mRNA and protein expression in MIA PaCa-2 cells by GEM. PaCa cells were treated with different concentrations of GEM $(0-20 \mu \mathrm{M})$ for $24 \mathrm{~h}$. a The CXCR4 mRNA levels in GEM-S and $\mathbf{b}$ in GEM-R were measured using RT-PCR (normalized to GAPDH expression). Values are expressed as means \pm SD. Multiple comparisons were performed by using one-way ANOVA followed by Dunnett's test. **, $P<0.01$; *, $P<0.05$ versus control $(0 \mu \mathrm{M})$. c-f The expression of CXCR4 protein in GEM-S and $\mathbf{g}$-j GEM-R was detected by immunostaining. CXCR4 (green) and DAPI (blue). Original magnification, $\times 200$

in stromal cells around GEM-R treated with GEM (Fig. 6k-n). CXCL12 IOD values in stromal cells around GEM-R PaCa cells treated with GEM were significantly enhanced compared with other groups $(P<0.01)$ (Additional file 2: Figure S2B).

The activity of NF-KB in GEM-R PaCa cells was enhanced by GEM

To examine the details of the molecular mechanisms, the activity of NF- $\mathrm{kB}$ in GEM-R/S PaCa cells was measured by NF- $\mathrm{B}$ (p65) transcription factor assay. The activity of NF-kB in GEM-R MIA PaCa-2 cells was significantly higher compared to GEM-S MIA PaCa-2 cells $(P<0.01)$ (Fig. 7a). Moreover, the activity of $N F-k B$ in GEM-R MIA PaCa-2 cells was significantly enhanced by GEM dose dependently (Fig. 7b).
Immunohistochemical analysis of HIF-1a in implanted tumor tissue

Similarly, since HIF-1 $\alpha$ might regulate the expression of CXCR4, we examined the expression of HIF-1 $\alpha$ in implanted tumor tissue. Staining of HIF-1 $\alpha$ protein in GEM-R cells treated with GEM was greatly enhanced (Fig. 7c). Significantly more HIF- $1 \alpha$-positive cells were observed in GEM-R cells treated with GEM than GEM$\mathrm{R}$ cells lacking such treatment $(P<0.01)$, GEM-S treated with GEM $(P<0.01)$ and GEM-S without GEM treatment $(P<0.01)$ (Fig. $7 \mathrm{~d})$.

The expression of CXCR7 mRNA in GEM-R PaCa cells Since CXCR7 is another receptor of CXCL12, we examined the CXCR7 expression in GEM-R/S MIA PaCa-2 cells by RT-PCR. In RT-PCR, the expression levels of 

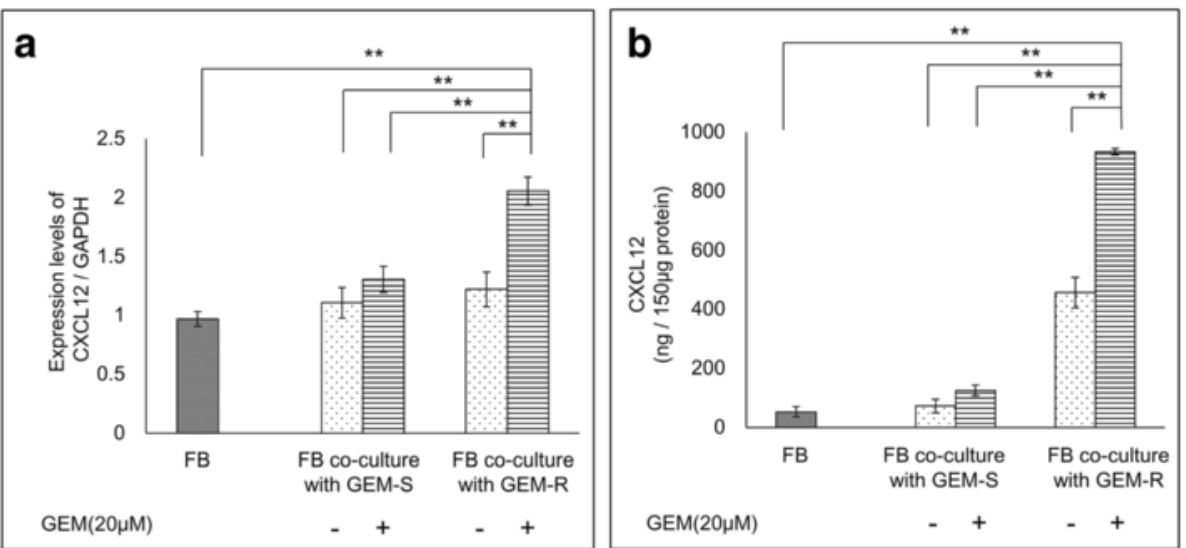

Fig. 4 Alteration of CXCL12 mRNA levels in fibroblasts (FB) resulting from co-culture with MIA PaCa-2 cells. FB were co-cultured for $24 \mathrm{~h}$ with GEM-R or GEM-S MIA PaCa-2 cells treated with or without GEM using a double-chamber method. a The mRNA levels of CXCL12 in FB were measured using RT-PCR (normalized to GAPDH expression). Furthermore, after FB were co-cultured with PaCa cells for $72 \mathrm{~h}$, the supernatants were collected from FB. $\mathbf{b}$ The concentrations of CXCL12 protein from FB were measured using an ELISA kit. Values are expressed as means \pm SD. Multiple comparisons were performed using one-way ANOVA followed by the Bonferroni test. ${ }^{* *}, P<0.01 ;{ }^{*}, P<0.05$

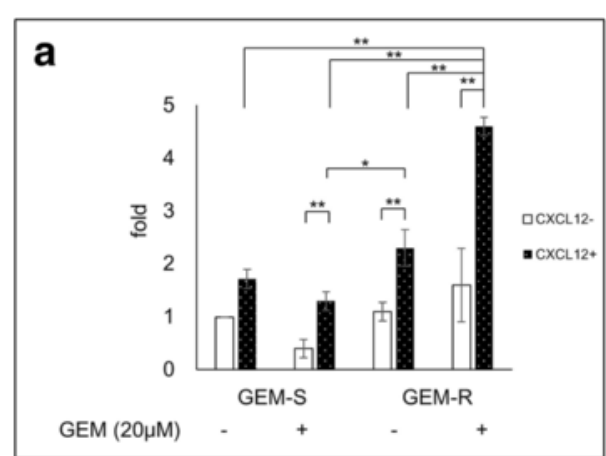

C

C
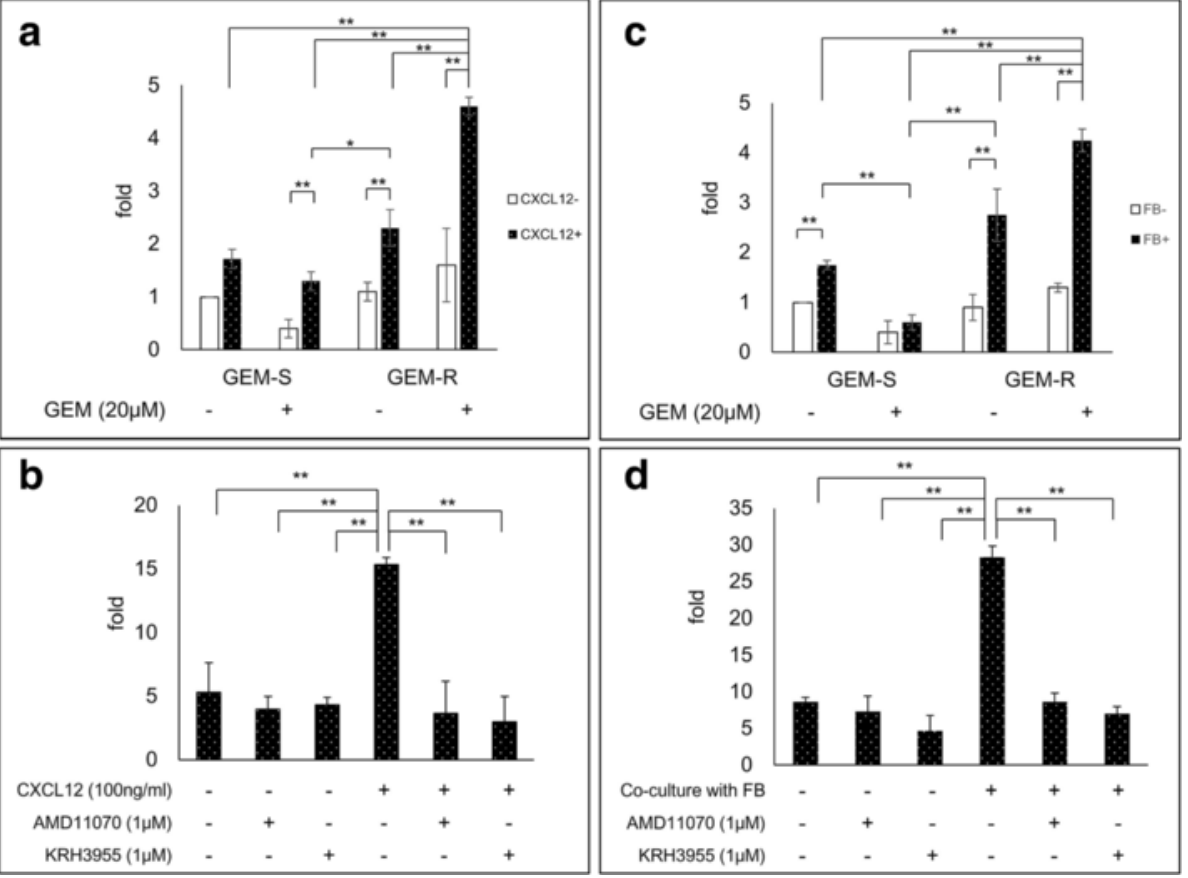

Fig. 5 Alteration of invasiveness of PaCa cells by CXCL12 stimulation and by co-culture with FB. The invasiveness of GEM-R and GEM-S MIA PaCa-2 cells was assessed by a double-chamber method using a Matrigel invasion assay system. PaCa cells were seeded into Matrigel pre-coated Transwell chambers. These cells were allowed to migrate for $22 \mathrm{~h}$. The cells that invaded through the membrane to the bottom of the upper chamber were fixed, stained, photographed and counted. The number of invading cells was counted in 5 random microscopic fields (200x). a The invasion assay was performed in basal medium containing recombinant CXCL12 (100 ng/mL) (c) and co-cultured with FB. b The effect of CXCR4 antagonists (AMD11070 and KRH3955) on the invasiveness of GEM-R PaCa cells treated with GEM activated by CXCL12 (d) and co-culturing with FB was examined. Values are expressed as means \pm SDs. Multiple comparisons were performed by using one-way ANOVA followed by Bonferroni test. **, $P<0.01 ;{ }^{*}, P<0.05$ 


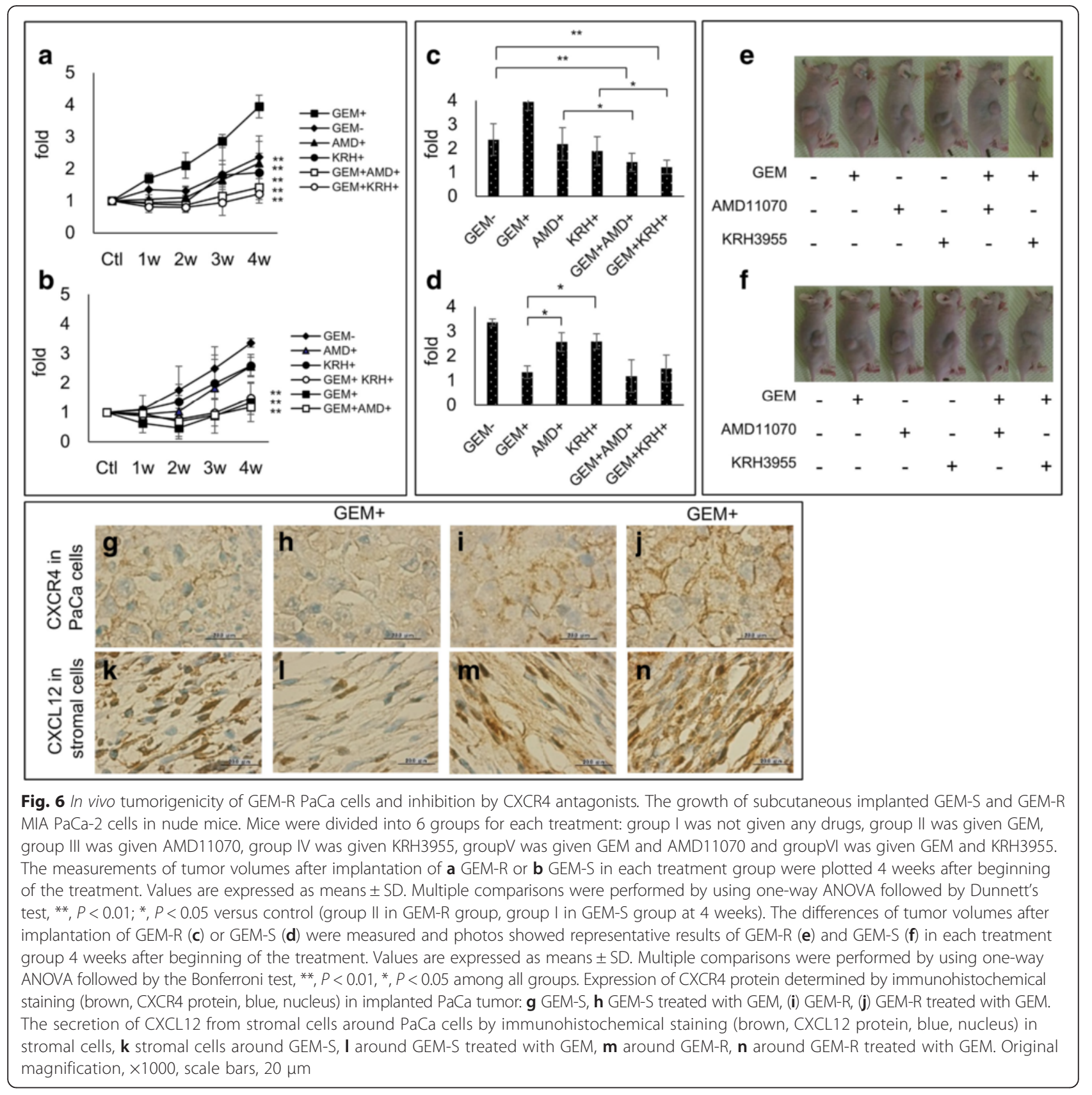

CXCR7 mRNA in GEM-R Mia PaCa-2 cells were significantly higher compared with GEM-S Mia PaCa- 2 cells. There was no change of CXCR7 mRNA levels by GEM treatment of both GEM-R/S Mia PaCa cells (Additional file 3: Figure S3).

\section{Discussion}

This study supports two conclusions. First, the resistance to GEM in PaCa cells was associated with activation of the CXCL12-CXCR4 signaling axis. Second, CXCR4 antagonists could inhibit the activation of the signaling axis and therefore restrain the invasive potency and tumorigenicity of GEM- $\mathrm{R}$ PaCa cells.

With regard to the first conclusion, the resistance to GEM in PaCa cells was associated with the activation of the CXCL12-CXCR4 signaling axis. Many different chemotherapeutic agents have failed to demonstrate any survival advantage in patients with $\mathrm{PaCa}$. GEM has been the current standard of care for PaCa patients [3]; however, it has never proven to be very effective clinically for advanced $\mathrm{PaCa}$ cases because of the cells' resistance to GEM. Improved therapeutic treatment will require a better understanding of the mechanisms by which these 

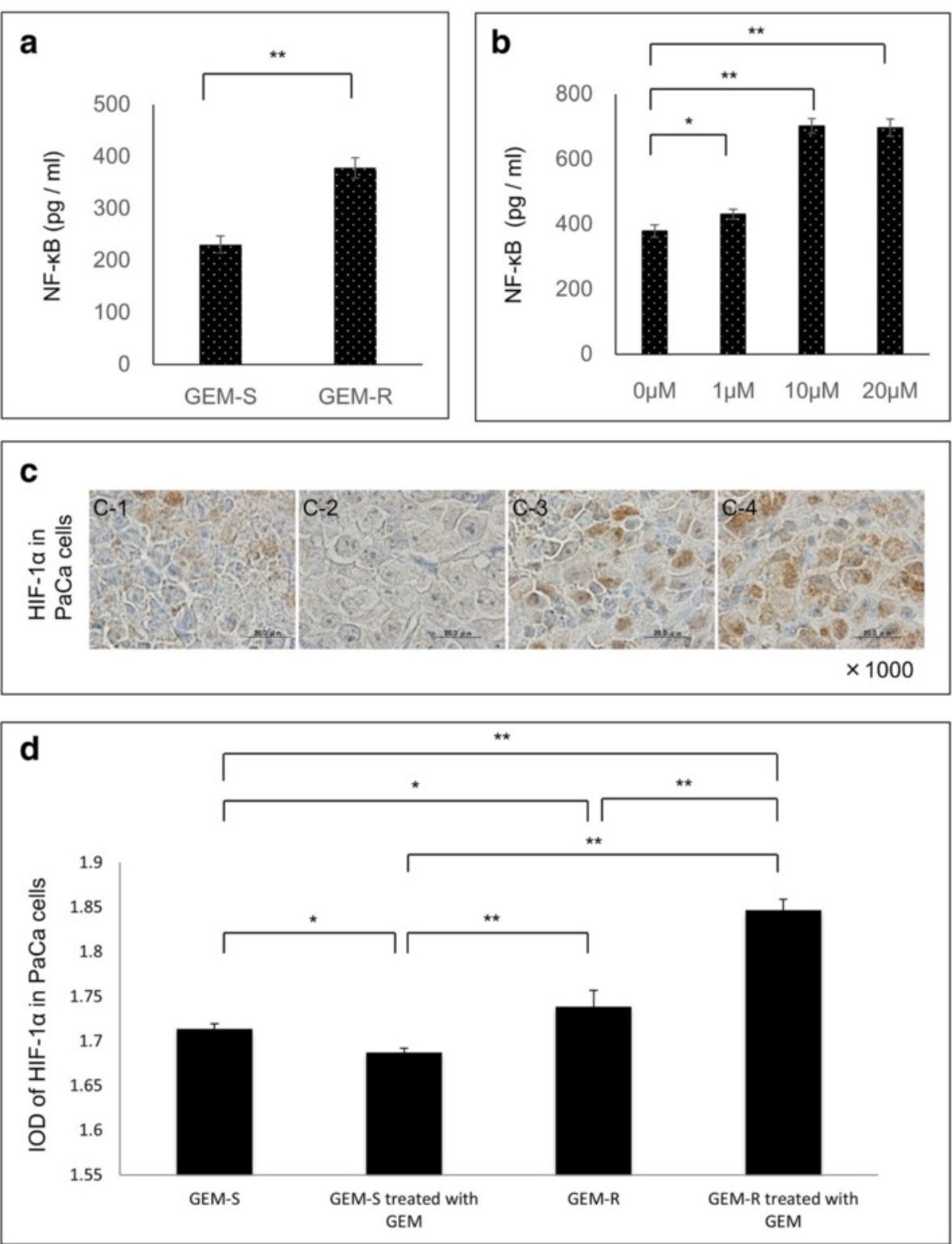

Fig 7 The expression of both NF-KB and HIF-1a in GEM-R and GEM-S PaCa cells. (a) The expression of NF-KB in GEM-R/S PaCa cells. The activity of NF-KB in GEM-R and GEM-S MIA PaCa-2 cells treated without GEM was measured by NF-KB (p65) transcription factor assay. Values are expressed as means $\pm \mathrm{SD}$. Between-group statistical significance was determined using the Student's $t$ test. ${ }^{*}, P<0.01$. (b) The effect of GEM on NF-KB activity in GEM-R PaCa cells. GEM-R MIA PaCa-2 cells were treated with different concentrations of GEM (0-20 $\mu \mathrm{M})$ for 72 h. The NF-kB p65 protein levels in GEM-R were measured. Values are expressed as means \pm SD. Multiple comparisons were performed by using one-way ANOVA followed by Dunnett's test. ${ }^{*}, P<0.01 ; *, P<0.05$ versus control $(0 \mu \mathrm{M})$. (c) The expression of HIF-1a in implanted PaCa tumor. The expression of HIF-1a protein determined by immunohistochemical staining (brown, HIF-1a protein, blue, nucleus) in implanted PaCa tumor: (c-1) GEM-S, (c-2) GEM-S treated with GEM, (c-3) GEM-R, (c-4) GEM-R treated with GEM. Original magnification, $\times 1000$, scale bars, $20 \mu \mathrm{m}$. (d) Quantification of immunostaining of HIF-1a protein by digital image analysis. For each image, the color deconvolution method was used to isolate HIF-1apositive DAB-stained cells from HIF-1a-negative hematoxylin-stained cells. The measurement parameter was IOD. Optical density was calibrated and the area of interest was set as follows: hue, 0-30; saturation, 0-255; intensity, 0-255. The values were determined, and the IOD was log 10 transformed. Values are expressed as means \pm SD. Multiple comparisons were performed using one-way ANOVA followed by Bonferroni test, ${ }^{* *}, P<0.01 ; *, P<0.05$

tumors become chemo-resistant and the development of strategies to overcome this resistance. Previous studies have suggested a variety of mechanisms of chemoresistance in $\mathrm{PaCa}$, including the deregulation of key signaling pathways (such as NF-kB [28], phosphatidylinositol 3kinase [PI3K]/Akt [29]), epithelial-mesenchymal transition (EMT) [30] and the presence of stromal cells [31]. In addition, a report suggested a relationship between 
CXCR4 and cancer stem cells. The report indicated that a subpopulation of migrating CD133+ CXCR4+ cancer stem cells was essential for tumor metastasis [32].

Recently, several studies detected the expression of CXCR4 and CXCL12 (also known as stromal-derived factor-1 [SDF-1]) in $\mathrm{PaCa}$ and stromal cells around $\mathrm{PaCa}$ cells. The CXCL12-CXCR4 signaling axis can promote $\mathrm{PaCa}$ tumorigenesis and chemoresistance in $\mathrm{PaCa}$ cells $[17,25,26]$. CXCR4, a member of the cell surface Gprotein-coupled, seven-span transmembrane receptor family, is overexpressed in more than 20 types of human tumors, including breast cancer, prostate cancer, colorectal cancer, melanoma, neuroblastoma, and renal cell carcinoma [7]. High expression of CXCR4 is observed in the majority of $\mathrm{PaCa}$ tissues, and precancerous lesions play a role in $\mathrm{PaCa}$ pathogenesis [33]. Furthermore, high expression of CXCR4 correlates with poorer survival in $\mathrm{PaCa}$ patients after resection [34]. CXCL12, a ligand for CXCR4, is a chemokine that is constitutively secreted by several organs including lung, liver, small intestine, kidney, prostate, brain and skeletal muscle [35]. High amounts of CXCL12 are produced by organs commonly affected by cancer metastasis, such as lung and liver [14]. In CXCR4-positive PaCa cell lines, CXCL12 not only enhances chemotaxis, transendothelial migration and Matrigel invasion, but also stimulates cell proliferation and protects them from serum deprivation-induced apoptosis [36-38].

We focused on the relationship between the activated CXCL12-CXCR4 signaling axis and PaCa cells' resistance to GEM. For that reason, we established two GEM$\mathrm{R} \mathrm{PaCa}$ cell lines. This is the first report to examine the importance of the CXCL12-CXCR4 signaling axis in resistance to GEM using GEM-R PaCa cells. Our study revealed that the expression of CXCR4 was significantly enhanced by GEM in GEM-R PaCa cells. Furthermore, when GEM-R PaCa cells were activated by GEM, they greatly increased the secretion of CXCL12 from FB. The invasiveness of GEM-R cells was also activated by CXCL12. In vivo, the tumorigenicity of GEM-R cells was enhanced by GEM. We confirmed that the CXCL12CXCR4 signaling axis between tumor and stromal cells plays an important role in the invasiveness and tumorigenicity of GEM-R PaCa cells.

The second conclusion of this study was that CXCR4 antagonists could inhibit the activation of the signaling axis and could therefore restrain the invasiveness and tumorigenicity of GEM-R PaCa cells. CXCR4 antagonists were initially developed as new drugs for the treatment of HIV-1 infection. Among them, AMD3100, a specific antagonist of CXCR4, was initially considered to interfere with HIV-1 fusion through coating [18]. However, limitations of AMD3100 include a relatively short halflife $(3.5-4.9 \mathrm{~h})$ and the need to administer it via injection [39]. Furthermore, after long-term use, cardiotoxicity was noticed in patients $[40,41]$. Due to those problems, clinical development was canceled. AMD11070 is a novel, orally bioavailable, selective, and reversible small-molecule antagonist of CXCR4 [19]. In vitro, it inhibits the binding of CXCL12 to CXCR4 and inhibits CXCL12-induced signaling mechanisms [42]. In two different ALL cells, equivalent concentrations of AMD11070 produced a stronger effect than AMD3100 [43]. Furthermore, no apparent acute toxicity was observed in oral bioavailability studies using AMD11070. The effectiveness of AMD11070 for malignant neoplasms was also reported in melanoma and lymphoblastic leukemia [43, 44]. Besides AMD11070, KRH3955 is also known as a CXCR4 antagonist. We decided to establish whether there was a similarity between the effect of KRH3955 and AMD11070. It was synthesized and purified by Kureha Corporation. KRH3955 showed oral bioavailability of $25.6 \%$ in rats, and its oral administration blocked X4 HIV-1 replication in human peripheral blood lymphocytes and in a severely immunodeficient mouse system. The effect of KRH3955 on HIV was much higher than that of AMD3100 and AMD11070 [20]. However, there are no studies on the effect of KRH3955 on other malignant diseases.

We focused on the effects of CXCR4 antagonists, AMD11070 and KRH3955, on the invasiveness and tumorigenicity of GEM-R PaCa cells and determined whether these agents might represent a second line of chemotherapy for GEM-R PaCa cells. Our study revealed that when the invasiveness and tumorigenicity of GEM-R PaCa cells were activated by GEM, it was inhibited by the CXCR4 antagonists in vitro and vivo.

Previous report demonstrated that CXCR4 up-regulation by gemcitabine correlated with time-dependent accumulation of NF-kB and HIF-1 $\alpha$ in the nucleus [45]. To examine the details of the molecular mechanisms, the activity of NF- $\kappa B$ in our GEM-R/S PaCa cells was measured by NF- $\mathrm{kB}$ (p65) transcription factor assay. The activity of NF- $\mathrm{BB}$ in GEM-R cells was significantly higher compared to GEM-S cells and was significantly enhanced by GEM dose dependently. Moreover, HIF- $1 \alpha$ expression in GEM-R cells treated with GEM was greatly enhanced compared with GEM-R non-treated and GEM-S cells. So we will elucidate further molecular mechanisms of GEM-resistance in the next study.

CXCR7 is another receptor of CXCL12. Also, it is reported that CXCR7 plays important role in cancer invasion [46]. So besides CXCR4, we examined the expression of CXCR7 in GEM-R/S PaCa cells. The expression of CXCR7 in GEM-R PaCa cells is higher than GEM-S PaCa cells. So we may say that to some extent CXCR7 plays a role in GEM resistance. We are going 
to elucidate the details of the mechanisms of CXCR7 for GEM-resistance in the near future.

\section{Conclusion}

In conclusion, we showed that GEM promoted the expression of CXCR4 in GEM-R PaCa cells and that activated GEM-R PaCa cells stimulated the secretion of CXCL12 from stromal cells. Finally, the CXCL12CXCR4 signaling axis in GEM-R PaCa cells was activated by cooperative interactions between activated GEM-R PaCa cells and stromal cells, and this activation promoted GEM-R PaCa cell proliferation, invasion and tumorigenicity. Importantly, we have demonstrated that even when GEM-R PaCa cells were activated by GEM, the blockage of the CXCL12-CXCR4 signaling axis by CXCR4 antagonists had impacts on GEM-R PaCa cell proliferation, invasion and tumorigenicity both in vitro and in vivo. Interestingly, these findings were observed only in GEM-R PaCa cells and not in GEM-S PaCa cells. As far as we know, this is the first study showing that one of several mechanisms of chemoresistance in $\mathrm{PaCa}$ cells involves chemokines and their receptor, CXCL12. We have shown that $C X C R 4$ antagonists can inhibit the development of GEM-R PaCa.

\section{Ethics approval and consent to participate}

All animal studies were conducted in accordance with the guidelines established by the internal Institutional Animal Care and Use Committee and Ethics Committee guidelines of Nagoya City University.

\section{Consent for publication}

Not applicable

\section{Availability of data and materials}

The datasets supporting the conclusion of this article are included within the article and its additional files.

\section{Additional files}

Additional file 1: Figure S1. Invasiveness of GEM-R and GEM-S PaCa cells and inhibition by CXCR4 antagonists. The photos showed alteration of invasiveness of PaCa cells by co-culturing with FB, and effect of CXCR4 antagonists, AMD11070 (1 $\mu \mathrm{M})$ and KRH3955 (1 $\mu \mathrm{M})$, on the invasiveness of PaCa cells. (JPG $874 \mathrm{~kb}$ )

Additional file 2: Figure S2. Quantification of immunostaining of CXCR4 and CXCL12 protein by digital image analysis. (A) The number of CXCR4 immunoreactive cells in mouse specimens was expressed as a percentage of the total number of cells that were randomly counted in 10 fields at $\times 400$ magnification. Furthermore, for each image, the color deconvolution method was used to isolate CXCL12-positive DAB-stained cells from CXCL12-negative hematoxylin-stained cells. The measurement parameter was IOD. Optical density was calibrated and the area of interest was set as follows: hue, 0-30; saturation, 0-255; intensity, 0-255. (B) The values were determined, and the IOD was $\log _{10}$ transformed. Values are expressed as means \pm SD. Multiple comparisons were performed using one-way ANOVA followed by Bonferroni test, ${ }^{* *}, P<0.01 ; *, P<0.05$. (JPG 295 kb)

Additional file 3: Figure S3. Alteration of $C X C R 7 \mathrm{mRNA}$ expression in MIA PaCa-2 cells by GEM. PaCa cells were treated with different concentrations of GEM (0-20 $\mu \mathrm{M})$ for $24 \mathrm{~h}$. The expression of CXCR7 in GEM-R and GEM-S PaCa cells treated without GEM (A) was measured using RT-PCR (normalized to GAPDH expression). Values are expressed as means $\pm S D$. Between-group statistical significance was determined using the Student's $t$ test. ${ }^{*}, P<0.01$. The $C X C R 7$ mRNA levels in GEM-S (B) and in GEM-R (C) were measured using RT-PCR (normalized to GAPDH expression). Values are expressed as means $\pm \mathrm{SD}$. Multiple comparisons were performed by using one-way ANOVA followed by Dunnett's test. **, $P<0.01 ;{ }^{*}, P<0.05$ versus control $(0 \mu \mathrm{M})$. (JPG $\left.374 \mathrm{~kb}\right)$

\section{Abbreviations}

PaCa: Pancreatic Cancer; GEM: Gemcitabine; GEM-R: Gemcitabine-Resistant; GEM-S: Gemcitabine-Sensitive; RT-PCR: reverse transcription polymerase chain reaction; ELISA: Enzyme Linked Immuno Solvent Assay; FB: Fibroblast cells; EMT: epithelial-mesenchymal transition; SDF-1: stromal-derived factor-1; DMEM: Dulbecco's Modified Eagle's Medium; RPMI-1640: Roswell Park Memorial Institute-1640; FBS: fetal bovine serum; IC50: the half maximal inhibitory concentration; DPEC: diethylpyrocarbonate; PBS: Phosphate Buffered Saline; DAB: 3,3-diaminobenzidine tetrahydrochloride; RGB: redgreen-blue; IOD: integrated optical density; SD: standard deviation; NFKB: Nuclear factor-kappa B; HIF-1a: Hypoxia-Inducible Factor-1a.

\section{Competing interests}

The authors declare that they have no competing interests.

\section{Authors' contributions}

Conception and design: MM, YM. Development of methodology: MM, YM, SK, KT, TS, TS, TS, HT, KS. Acquisition of data: MM, YM, SK. Analysis and interpretation of data: MM, YM, SK. Writing, review, and/or revision of the manuscript: MM, YM, HT. Administrative, technical, or material support: YM, HT. Study supervision: YM. All authors read and approved the final manuscript.

\section{Acknowledgements}

The authors would like to thank JAM POST (http://www.jamp.com/) for the English language review.

\section{Funding}

This work was supported by JSPS KAKENHI Grant Number 15 K10192.

Received: 12 October 2015 Accepted: 8 May 2016

Published online: 12 May 2016

References

1. Siegel R, Naishadham D, Jemal A. Cancer statistics, 2013. CA Cancer J Clin. 2013:63:11-30.

2. Hidalgo M. Pancreatic cancer. N Engl J Med. 2010;362:1605-17.

3. Burris 3rd HA, Moore MJ, Andersen J, Green MR, Rothenberg ML, Modiano $M R$, et al. Improvements in survival and clinical benefit with gemcitabine as first-line therapy for patients with advanced pancreas cancer: a randomized trial. J Clin Oncol. 1997;15:2403-13.

4. Wong HH, Lemoine NR. Pancreatic cancer: molecular pathogenesis and new therapeutic targets. Nat Rev Gastroenterol Hepatol. 2009;6:412-22

5. Matsuo Y, Ochi N, Sawai H, Yasuda A, Takahashi H, Funahashi $H$, et al. CXCL8/IL-8 and CXCL12/SDF-1alpha co-operatively promote invasiveness and angiogenesis in pancreatic cancer. Int J Cancer. 2009;124:853-61.

6. Murphy PM. Chemokines and the molecular basis of cancer metastasis. N Engl J Med. 2001;345:833-5.

7. Balkwill F. The significance of cancer cell expression of the chemokine receptor CXCR4. Semin Cancer Biol. 2004;14:171-9.

8. Homey B, Müller A, Zlotnik A. Chemokines: agents for the immunotherapy of cancer? Nat Rev Immunol. 2002;2:175-84.

9. Kulbe H, Levinson NR, Balkwill F, Wilson JL. The chemokine network in cancer-much more than directing cell movement. Int J Dev Biol. 2004:48: 489-96. 
10. Burger JA, Kipps TJ. CXCR4: a key receptor in the crosstalk between tumor cells and their microenvironment. Blood. 2006;107:1761-7.

11. Strieter RM. Chemokines: not just leukocyte chemoattractants in the promotion of cancer. Nat Immunol. 2001;2:285-6.

12. Hall JM, Korach KS. Stromal cell-derived factor 1, a novel target of estrogen receptor action, mediates the mitogenic effects of estradiol in ovarian and breast cancer cells. Mol Endocrinol. 2003;17:792-803.

13. Barbero S, Bonavia R, Bajetto A, Porcile C, Pirani P, Ravetti JL, et al. Stromal cell-derived factor 1alpha stimulates human glioblastoma cell growth through the activation of both extracellular signal-regulated kinases 1/2 and Akt. Cancer Res. 2003;63:1969-74.

14. Muller A, Homey B, Soto H, Ge N, Catron D, Buchanan ME, et al. Involvement of chemokine receptors in breast cancer metastasis. Nature. 2001;410:50-6.

15. Koshiba T, Hosotani R, Miyamoto Y, Ida J, Tsuji S, Nakajima S, et al. Expression of stromal cell-derived factor 1 and CXCR4 ligand receptor system in pancreatic cancer: a possible role for tumor progression. Clin Cancer Res. 2000;6:3530-5

16. Sun YX, Wang J, Shelburne CE, et al. Expression of CXCR4 and CXCL12 (SDF1) in human prostate cancers (P Ca) in vivo. J Cell Biochem. 2003:89:462-73.

17. Singh S, Srivastava SK, Bhardwaj A, Owen LB, Singh AP. CXCL12-CXCR4 signalling axis confers gemcitabine resistance to pancreatic cancer cells: a novel target for therapy. Br J Cancer. 2010;103:1671-9.

18. De Clercq E. The bicyclam AMD3100 story. Nat Rev Drug Discov. 2003;2: 581-7.

19. Skerlj RT, Bridger GJ, Kaller A, McEachern EJ, Crawford JB, Zhou Y, et al. Discovery of novel small molecule orally bioavailable C-X-C chemokine receptor 4 antagonists that are potent inhibitors of T-tropic (X4) HIV-1 replication. J Med Chem. 2010;53:3376-88.

20. Murakami T, Kumakura S, Yamazaki T, Tanaka R, Hamatake M, Okuma K, et al. The novel CXCR4 antagonist KRH-3955 is an orally bioavailable and extremely potent inhibitor of human immunodeficiency virus type 1 infection: comparative studies with AMD3100. Antimicrob Agents Chemother. 2009:53:2940-8.

21. Cabioglu N, Summy J, Miller C, Parikh NU, Sahin AA, Tuzlali S. CXCL12/ stromal cell-derived factor-1alpha transactivates HER2-neu in breast cancer cells by a novel pathway involving Src kinase activation. Cancer Res. 2005; 65:6493-7.

22. Hartmann TN, Burger JA, Glodek A, Fujii N, Burger M. CXCR4 chemokine receptor and integrin signaling co-operate in mediating adhesion and chemoresistance in small cell lung cancer (SCLC) cells. Oncogene. 2005;24: 4462-71.

23. Ohira S, Sasaki M, Harada K, Sato Y, Zen Y, Isse K. Possible regulation of migration of intrahepatic cholangiocarcinoma cells by interaction of CXCR4 expressed in carcinoma cells with tumor necrosis factor-alpha and stromalderived factor-1 released in stroma. Am J Pathol. 2006;168:1155-68.

24. Yasumoto K, Koizumi K, Kawashima A, Saitoh Y, Arita Y, Shinohara K. Role of the CXCL12/CXCR4 axis in peritoneal carcinomatosis of gastric cancer. Cancer Res. 2006:66:2181-7.

25. Marchesi F, Monti P, Leone BE, Zerbi A, Vecchi A, Piemonti L. Increased survival, proliferation, and migration in metastatic human pancreatic tumor cells expressing functional CXCR4. Cancer Res. 2004;64:8420-7.

26. Saur D, Seidler B, Schneider G, Algül H, Beck R, et al. CXCR4 expression increases liver and lung metastasis in a mouse model of pancreatic cancer. Gastroenterology. 2005;129:1237-50.

27. Zhang H, Zhang L, Chen L, Li W, Li F, Chen Q. Stromal cell-derived factor-1 and its receptor CXCR4 are upregulated expression indegenerated intervertebral discs. Int J Med Sci. 2014;11:240-5.

28. Banerjee S, Wang Z, Kong D, Sarkar FH. 3,3'-Diindolylmethane enhances chemosensitivity of multiple chemotherapeutic agents in pancreatic cancer. Cancer Res. 2009;69:5592-600.

29. Ng SSW, Tsao MS, Chow S, Hedley DW. Inhibition of phosphatidylinositide 3-kinase enhances gemcitabine-induced apoptosis in human pancreatic cancer cells. Cancer Res. 2000;60:5451-5.

30. Ellenrieder V, Hendler SF, Boeck W, Seufferlein T, Menke A, Ruhland C, et al. Transforming growth factor beta1 treatment leads to an epithelialmesenchymal transdifferentiation of pancreatic cancer cells requiring extracellular signal-regulated kinase 2 activation. Cancer Res. 2001;61:4222-8.

31. Hwang RF, Moore T, Arumugam T, Ramachandran V, Amos KD, Rivera A, et al. Cancer-associated stromal fibroblasts promote pancreatic tumor progression. Cancer Res. 2008;68:918-26.
32. Hermann PC, Huber SL, Herrler T, Aicher A, Ellwart JW, Guba M, et al. Distinct populations of cancer stem cells determine tumor growth and metastatic activity in human pancreatic cancer. Cell Stem Cell. 2007;1: 313-23.

33. Singh S, Sadanandam A, Singh RK. Chemokines in tumor angiogenesis and metastasis. Cancer Cancer Metastasis Rev. 2007;26:453-67.

34. Maréchal R, Demetter P, Nagy N, Berton A, Decaestecker C, Polus M, et al. High expression of CXCR4 may predict poor survival in resected pancreatic adenocarcinoma. Br J Cancer. 2009:100:1444-51.

35. Wu PF, Lu ZP, Cai BB, Tian L, Zou C, Jiang KR, et al. Role of CXCL12/CXCR4 signaling axis in pancreatic cancer. Chin Med J (Engl). 2013;126:3371-4.

36. Katsumoto K, Kume $\mathrm{S}$. The role of CXCL12-CXCR4 signaling pathway in pancreatic development. Theranostics. 2013;3:11-7.

37. Mori T, Doi R, Koizumi M, Toyoda E, Ito D, Kami K, et al. CXCR4 antagonist inhibits stromal cell-derived factor 1-induced migration and invasion of human pancreatic cancer. Mol Cancer Ther. 2004;3:29-37.

38. Teicher BA, Fricker SP. CXCL12 (SDF-1)/CXCR4 pathway in cancer. Clin Cancer Res. 2010;16:2927-31.

39. Hendrix CW, Flexner C, MacFarland RT, Giandomenico C, Fuchs EJ, Redpath E, et al. Pharmacokinetics and safety of AMD-3100, a novel antagonist of the CXCR4 chemokine receptor, in human volunteers. Antimicrob Agents Chemother. 2000:44:1667-73.

40. Hendrix CW, Collier AC, Lederman MM, Schols D, Pollard RB, Brown S, et al. Safety, pharmacokinetics, and antiviral activity of AMD3100, a selective CXCR4 receptor inhibitor, in HIV-1 infection. J Acquir Immune Defic Syndr. 2004;37:1253-62.

41. Scozzafava A, Mastrolorenzo A, Supuran CT. Non-peptidic chemokine receptors antagonists as emerging anti-HIV agents. J Enzyme Inhib Med Chem. 2002;17:69-76.

42. Mosi RM, Anastassova V, Cox J, Darkes MC, Idzan SR, Labrecque J, et al. The molecular pharmacology of AMD11070: an orally bioavailable CXCR4 HIV entryinhibitor. Biochem Pharmacol. 2012;83:472-9.

43. Parameswaran R, Yu M, Lim M, Groffen J, Heisterkamp N. Combination of drug therapy in acute lymphoblastic leukemia with a CXCR4 antagonist Leukemia. 2011:25:1314-23.

44. O'Boyle G, Swidenbank I, Marshall H, Barker CE, Armstrong J, White SA, et al. Inhibition of CXCR4-CXCL12 chemotaxis in melanoma by AMD11070. Br J Cancer. 2013;108:1634-40.

45. Arora S, Bhardwaj A, Singh S, Srivastava SK, McClellan S, Nirodi CS, et al. An undesired effect of chemotherapy: gemcitabine promotes pancreatic cancer cell invasiveness through reactive oxygen species-dependent, nuclear factor KB- and hypoxia-inducible factor 1a-mediated up-regulation of CXCR4. J Biol Chem. 2013;288:21197-207

46. Guo F, Wang Y, Liu J, Mok SC, Xue F, Zhang W. CXCL12/CXCR4: a symbiotic bridge linking cancer cells and their stromal neighbors in oncogenic commnucation networks. Oncogene. 2015. doi:10.1038/onc.2015.139 [Epub ahead of print].

\section{Submit your next manuscript to BioMed Central and we will help you at every step:}

- We accept pre-submission inquiries

- Our selector tool helps you to find the most relevant journal

- We provide round the clock customer support

- Convenient online submission

- Thorough peer review

- Inclusion in PubMed and all major indexing services

- Maximum visibility for your research

Submit your manuscript at www.biomedcentral.com/submit 